\title{
Combating COVID-19: health equity matters
}

\author{
COVID-19 has affected vulnerable populations disproportionately across China and the world. Solid social and \\ scientific evidence to tackle health inequity in the current COVID-19 pandemic is in urgent need.
}

\section{Zhicheng Wang and Kun Tang}

T he outbreak of the respiratory disease COVID-19 in China has caused global concern ${ }^{1}$. By 24 February 2020, the number of confirmed infections nationwide had reached 77,658, of which 64,786 were in Hubei province (with 47,071 in Wuhan city). The Chinese government's massive lockdown and travel-restriction measures have already seen preliminary effects ${ }^{2}$. However, the overstretch of the health system's capacity within the epicenter, especially in Wuhan city, has already led to a large discrepancy in the case-fatality rate in Hubei province (3.96\%), which is about 5 times that of other provinces in China $(0.79 \%)$ and 3.6 times that of the rest of the world $(1.11 \%)^{3,4}$. Developing an equitable health system is at the core of the principles and goals of the Healthy China 2030 plan and the Sustainable Development Goals ${ }^{5,6}$. The global efforts to contain the epidemic cannot ignore health equity, especially at the epicenter, where the outbreak is still ongoing. Ensuring equal treatment opportunities for all is key to winning this battle.

Financial protection during outbreak matters. At the initial stage of the COVID-19 epidemic, out-of-pocket expenditure posed a substantial financial burden for the poor populations with severe symptoms, even for those under coverage by the social health insurance scheme. On 22 January 2020 , after realizing the severity of the outbreak, the National Healthcare Security Administration and Ministry of Finance immediately issued a notice to guarantee that the out-of-pocket medical expenses of all patients confirmed to have COVID-19 would be subsidized by the government, and this policy was later extended to all suspected cases ${ }^{7}$. The removal of catastrophic medical expenditures cleared the financial barriers for patients with both confirmed and suspected cases of COVID-19 to seek medical treatment right away while also protecting them from being impoverished by the infection. However, perhaps more importantly, it ensured that the disease-control efforts reached out to the most marginalized and vulnerable people to contain the spread of the causative coronavirus.

However, financial protection is only one aspect of achieving health equity during this outbreak. The overloaded clinical capacity, although supplemented with thousands of health workers from other provinces, could not meet the demand of COVID-19 screening and treatment at the initial stage of the epidemic in Wuhan city. Many patients with COVID-19 symptoms posted 'Help me' messages through social media, seeking treatment opportunities. Social media can be a useful channel for those with good internet literacy, but for those who have no access to the internet, especially among the elderly, the chance of being hospitalized was slim. After the lockdown of Wuhan city and Hubei province, people with suspected COVID-19 were ordered to self-quarantine at home, awaiting hospitalization. This situation resembles the Chicago heat wave in 1995, during which those who lived alone or had little social capital were more likely to die from the disaster ${ }^{8}$. In addition, timely treatment also depends on the effective operation of communities. The lack of community capacity and mobilization in the deprived regions may be another key bottleneck to providing timely assistance to patients and the affected families, as was seen in the H1N1 influenza epidemic in the USA? This may also explain the disproportionally high level of morbidity and mortality in particular cities and provinces, in contrast to that in other parts of China.

Apart from the immediate health effects for the vulnerable populations, the epidemic will inevitably have long-term socioeconomic impacts on both the people infected and the communities in which they live. The outbreak of cholera in London in 1854, for example, is still believed to exert negative economic consequences on neighborhoods and the city ${ }^{10}$. The livelihoods of the vulnerable groups living in deprived areas are severely affected by the epidemic. The decrease in income will in turn harm their future health ${ }^{11}$. If this vicious cycle is not broken, the problems of local health inequity in the epidemic areas will remain or could even be exacerbated.

Solid evidence for tackling health inequities during the COVID-19 outbreak is in urgent need. The scarcity of health-equity assessment during the current outbreak will halve the disease-control efforts. In the future, we suggest adopting a stronger and more rapid social-science approach in support of research on the 'social autopsy' of the COVID-19 outbreak ${ }^{12}$. We believe health equity should be at the center of all policies designed to strengthen China's health system and emergency responses during the current epidemics and other public-health crises in the future.

\section{Zhicheng Wang and Kun Tang ${ }^{凶}$ Research Center for Public Health, School of Medicine, Tsinghua University, Beijing, China.

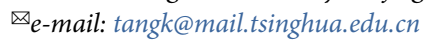

Published online: 26 March 2020 https://doi.org/10.1038/s41591-020-0823-6

\section{References}

1. Wang, C., Horby, P. W., Hayden, F. G. \& Gao, G. F. Lancet 395, 470-473 (2020).

2. Xinhua News http://www.xinhuanet.com/english/202002/25/c_138815982.htm (25 February 2020).

3. National Health Commission of the People's Republic of China. http://en.nhc.gov.cn/2020-02/25/c_76890.htm (25 February 2020).

4. World Health Organization. https://www.who.int/docs/defaultsource/coronaviruse/situation-reports/20200224-sitrep-35covid-19.pdf?sfvrsn=1ac4218d_2 (25 February 2020).

5. State Council. LexisNexis http://china.lexiscn.com/law/lawenglish-1-2961294-T.html (25 October 2016).

6. Marmot, M. \& Bell, R. Epidemiology 29, 5-7 (2018).

7. National Healthcare Security Administration. http://www.gov.cn/ xinwen/2020-01/30/content_5473177.htm (18 February 2020).

8. Semenza, J. C. et al. N. Engl. J. Med. 335, 84-90 (1996).

9. Lowcock, E. C., Rosella, L. C., Foisy, J., McGeer, A. \& Crowcroft, N. Am. J. Public Health 102, e51-e58 (2012).

10. Ambrus, A., Field, E. \& Gonzalez, R. Am. Econ. Rev. 110, 475-525 (2020).

11. Marmot, M. Health Aff. (Millwood) 21, 31-46 (2002).

12. Klinenberg, E. Heat Wave: A Social Autopsy of Disaster in Chicago (University of Chicago Press, 2015).

Competing interests

The authors declare no competing interests. 